\title{
REFLEXÃO ACERCA DA VIOLÊNCIA ESTATAL: POSSÍVEL ARTICULAÇÃO ENTRE HANNAH ARENDT E MICHEL FOUCAULT
}

Priscila da Silva*

Resumo: O presente trabalho objetiva evidenciar a violência estatal em trechos da obra de Hannah Arendt e Michel Foucault. Da primeira será utilizada a parte dois do capítulo V, intitulada "O declínio do Estado-Nação e o fim dos Direitos do Homem" presente no livro "Origens do Totalitarismo". Quanto ao segundo, a reflexão tomará a Aula de 17 de março de 1976, constante do curso "Em Defesa da Sociedade", proferido no Collège de France. Ao se colocar em relevo o que cada autor apresenta como a manifestação do direito de espada do soberano, pretende-se apontar as semelhanças e as diferenças, estabelecendo-se, assim, um possível diálogo entre autores que, embora contemporâneos, desenvolveram suas obras de forma independente.

Palavras-chave: Michel Foucault; Hannah Arendt; violência estatal; biopolítica.

A analítica foucaultiana das relações de poder produziu um deslocamento na compreensão do campo político. De uma concepção estritamente jurídica do poder, baseada no cerceamento, na renúncia e na manifestação faustosa da soberania, passamos a considerar o poder também em seu caráter estratégico no qual o embate agônico de forças dissimétricas produz efeitos concretos. Contudo, a violência ainda é uma sombra que paira sobre o problema do poder, quer em sua faceta mais brutal como pudemos acompanhar com horror nos genocídios perpetrados pelo nazi-fascismo, quer em sua modalidade dispersa e insidiosa presente na ação policial contra jovens moradores das periferias brasileiras. Por isso, é urgente promover essa discussão. Para tanto, este trabalho busca evidenciar a violência estatal em trechos da obra de Hannah Arendt e Michel Foucault. Da primeira será utilizada a parte dois do capítulo V, intitulada "O declínio do Estado-Nação e o fim dos Direitos do Homem" presente no livro "Origens do Totalitarismo". Quanto ao segundo, a reflexão tomará a Aula de 17 de março de 1976, constante do curso "Em Defesa da Sociedade", proferido no Collège de France. Ao se colocar em relevo o que cada autor apresenta como a manifestação do direito de espada do soberano, pretende-se apontar as semelhanças e as diferenças, estabelecendo-se,

\footnotetext{
${ }^{*}$ Mestre em Filosofia - UNIFESP. Este trabalho decorre de pesquisa de mestrado financiada pela CAPES. Este texto foi publicado na Revista Theoria (Pouso Alegre), v. VI, p. 130-139, 2014. Contato: priscilafilo13@gmail.com
} 
assim, um possível diálogo entre autores que, embora contemporâneos, desenvolveram suas obras de forma independente.

Segundo Hannah Arendt, a reconfiguração dos Estados-nacionais no entre guerras produziu efeitos singulares, entre os quais a depauperização dos pequenos proprietários de terras e o desemprego em massa. Porém, Arendt destaca o surgimento de grupos de pessoas cuja desqualificação política e condição errante colocaram em relevo o paradoxo dos Direitos do Homem, pois estes - apesar de apresentarem o Homem como a fonte da Lei e seu objetivo último - se mostraram eficazes apenas para aqueles que se encontravam e eram reconhecidos como pertencentes ao âmbito jurídico-legal de um Estado. Pois isso era justamente o que faltava àqueles que foram denominados de apátridas - os povos sem estado - os quais não "dispunham de governos que os representassem e protegessem e, por isso, eram forçados a viver sob as leis de exceção dos Tratados das Minorias [...] ou sob condições de absoluta ausência da lei" (ARENDT, 1989, p. 302), ou seja, os apátridas foram destituídos de direitos tidos como "inalienáveis, irredutíveis e indeduzíveis de outros direitos ou leis" (idem, p. 324).

Esta condição de absoluta vulnerabilidade dos povos sem estado marcou "a transformação do Estado de instrumento da lei em instrumento da nação" (idem, p. 307-308) - o que Arendt reconhece como condição intrínseca à estrutura Estado-nação, no qual apesar de fundado na legalidade, os interesses da nação, ou do povo, se sobrepõem às leis.

Ademais, no limite, esta sobreposição dos interesses da nação sobre o ordenamento desembocou na peculiar situação: a constituição de um grupo de pessoas cujo não pertencimento à tríade Estado-povo-território os colocava simultaneamente num estado de total rejeição e, entretanto, indeportabilidade, já que nenhum governo queria receber estes contingentes cada vez mais numerosos. Este impasse impulsionou a instauração do Estado de exceção. Cito Arendt

Pode parecer que essa indeportabilidade de uma pessoa sem Estado impedisse um governo de expulsá-la; mas, como o homem sem Estado - um fora-da-lei por definição - era uma 'anomalia para a qual não existia posição apropriada na estrutura da lei geral', ficava completamente à mercê da polícia, que, por sua vez, não hesitava muito em cometer atos ilegais para diminuir a carga de indésirables no país. Em outras palavras, o Estado, insistindo em seu soberano direito de expulsão, era forçado, pela natureza ilegal da condição de apátrida, a cometer atos confessadamente ilegais (1989, p. 317).

Porém, a autora afirma que o germe totalitário se manifesta naqueles Estados em que o princípio de igualdade perante a lei é inexistente ou foi dissolvido. Porque

[...] sem essa igualdade legal, que originalmente se destinava a substituir as leis e ordens mais antigas da sociedade feudal, a nação se dissolve numa massa anárquica de indivíduos super e subprivilegiados. As leis que não são 
iguais para todos transformam-se em direitos e privilégios, o que contradiz a própria natureza do Estado-nação. Quanto mais clara é a demonstração da sua incapacidade de tratar os apátridas como 'pessoas legais', e quanto mais extenso é o domínio arbitrário do decreto policial, mais difícil é para os Estados resistir à tentação de privar todos os cidadãos da condição legal e dominá-los com uma polícia onipotente (ARENDT, 1989, p. 323-324).

Ou seja, apesar de reconhecer na estrutura Estado-nação a tendência dos interesses do povo se sobreporem às leis, Arendt insiste que o Estado de exceção é instaurado quando o ordenamento não prevê proteção àqueles que não podem ou não querem ser incluídos no grupo considerado como cidadãos legítimos de um Estado soberano, "sua situação angustiante não resulta do fato de não serem iguais perante a lei, mas sim de não existirem mais leis para eles" (ARENDT, 1989, p. 329). Curiosamente, na medida em que o contingente de pessoas sem lugar aumentava, até mesmo o direito de asilo recuou até a beira da total ineficácia ou, nas palavras de Arendt, "levando uma existência mais ou menos irreal" (idem, p. 314).

Com efeito, para que a vida destes refugiados ou apátridas estivesse à disposição do soberano - fossem vidas matáveis - era necessária a suspensão paulatina de sua condição legal, isto é, era necessária sua expulsão do ordenamento, o estabelecimento de "uma condição de completa privação de direitos antes que o direito à vida fosse ameaçado" (idem, p. 329). Nesse sentido, o nazismo apresenta um exemplo cristalino:

\begin{abstract}
Os próprios nazistas começaram a sua exterminação dos judeus privando-os, primeiro, de toda condição legal (isto é, da condição de cidadãos de segunda classe) e separando-os do mundo para ajuntá-los em guetos e campos de concentração; e, antes de acionarem as câmaras de gás, haviam apalpado cuidadosamente o terreno e verificado, para sua satisfação, que nenhum país reclamava aquela gente (ARENDT, 1989, p. 329).
\end{abstract}

Com isso, perguntamo-nos se é possível afirmar que para Hannah Arendt o vácuo legal é a condição de possibilidade para a manifestação do poder soberano de fazer morrer; de tal forma que a violência estatal seja correlata da impossibilidade das instituições legais de um Estado em acolher os casos excepcionais, isto é, o exercício do direito soberano de espada dependeria das circunstâncias não sendo, pois, decorrente do funcionamento normal do Estado. Embora Arendt tenha defendido neste mesmo texto que "o surgimento de governos totalitários é um fenômeno interno, e não externo, da civilização.” (idem, p. 336), acreditamos que esta inquietação é legítima porque Arendt frisa o caráter de ruptura presente na manifestação da violência estatal.

Em Foucault temos uma situação diferente. Para ele, existe um vínculo fundamental entre o direito soberano de matar e o biopoder e "tal jogo está efetivamente inscrito no funcionamento de todos os Estados" (FOUCAULT, 1999, p. 312). Esta asserção, evidentemente, alude tanto aos Estados autoritários quanto aos Estados democráticos, e é na inclusão destes últimos que reside sua singularidade. Vejamos como Foucault constrói seu argumento. 
Segundo Foucault, entre o final do século XVIII e início do século XIX se produziu uma novidade política, isto é

a assunção da vida pelo poder [...], uma tomada de poder sobre o homem enquanto ser vivo, uma espécie de estatização do biológico ou, pelo menos, uma certa inclinação que conduz ao que se poderia chamar de estatização do biológico (idem, p. 286).

Entretanto, convém esclarecer que já não se trata daquela vida fundadora do contrato social em que os indivíduos se reuniam e decidiam conceder ao soberano sua força, seu poder de matar. Esta transferência, este consentimento, tinha como objetivo preservar, proteger a vida de cada um dos indivíduos participantes do contrato. Contudo, para Foucault, na velha configuração soberana, o investimento sobre a vida exercia-se, de fato, em sua negatividade porque era pela imposição da morte que o rei dispunha da vida dos súditos, através do direito de espada o soberano marcava sua atuação e manifestava-se em todo seu esplendor; enquanto que no deixar morrer o soberano se abstinha, deixava de atuar, o viver era o silêncio e a opacidade da soberania.

Além desse desequilíbrio - a morte como realização da potência soberana, ao passo que a vida como sua indiferença, ou recuo - o investimento sobre a vida por meio de sua extinção legitimava o lugar de exceção do soberano em relação ao conjunto dos homens, cuja vontade coletiva deu origem e sustenta esta assimetria. Pois, conforme a teoria clássica - pelo menos a hobbesiana - o contrato social, grosso modo, fundava-se no consentimento ao soberano de um poder sobre a vida dos participantes do contrato. Ocorre que esta concessão implicava na abstenção da potência mortífera presente em cada indivíduo. Com efeito, exigia-se a cada contratante sua renúncia ao poder de apreensão e até mesmo supressão das coisas, segundo interesses egoístas; porém, esta potência mortífera não desaparece, pois é transferida e multiplicada na figura do soberano. Nesse sentido, Foucault defende que - na formulação teórica clássica - o soberano deveria investir a vida por sua negatividade ao exercer seu "direito de matar ou contendo-o; só marca seu poder sobre a vida pela morte que tem condições de exigir. O direito que é formulado como 'de vida e morte' é, de fato, o direito de causar a morte ou de deixar viver" (FOUCAULT, 1988, p. 148). Assim, em função do coletivo - da reunião das forças de cada indivíduo contratante que são concedidas ao soberano - é que se pode dizer que o soberano possui um direito de espada, isto é, "ele pode fazer morrer e deixar viver" (FOUCAULT, 1999, p. 286).

Ora, Foucault não aponta o desaparecimento deste direito de espada do soberano, mas sim defende que ao lado deste direito um novo poder, uma nova função política surge no final do século XIX, qual seja, o direito de "fazer viver e deixar morrer" (1999, p. 287).

Nesta nova tecnologia de poder - chamada de biopolítica - combinam-se dois modelos, duas formas de investimento político que, a partir de estratégias distintas, diametralmente opostas, permitem o cerco da vida em seus múltiplos aspectos. O primeiro é o modelo disciplinar. Este se baseia na produção do corpo-máquina através do adestramento, vigilância, esquadrinhamento e subjetivação, num movimento constante e sempre reiniciado. Com esses 
procedimentos, busca-se um nível ótimo de desempenho que traduza o fino balanço entre o aumento das forças disponíveis para a produção capitalista e a simultânea diminuição das resistências. Em suma, produção de corpos-sujeitos dóceis e úteis, num insistente enquadramento do corpo social em cujas margens se acumulam os recalcitrantes, os rebeldes e os incapazes, todos reunidos sob a pecha da anormalidade que, no entanto, não os exclui do sistema, mas instaura uma constante e insistente tentativa de correção.

O segundo modelo é o regulamentador. Neste, trata-se de gerenciar o corpo-espécie da população através da intervenção sobre as funções biológicas, os processos vitais. Emergem mecanismos de acompanhamento e intervenção sobre fenômenos como a natalidade, a mortandade, a longevidade, todos considerados segundo cálculos estatísticos. Não se trata de intervir ininterruptamente como nos dispositivos disciplinares. Mas agir fundamentando-se na lógica de incremento sanitário da população, isto quando a análise, o balanço entre os riscos e as vantagens de um fenômeno delineia uma situação em que a ação visa combater os perigos, os excessos. Ou seja, no mecanismo biopolítico a administração é contínua e generalizada, porém a intervenção é pontual, entretanto mais invasiva e profunda.

Com efeito, a análise foucaultiana não pretende discutir a teoria política, mas, sobretudo, assinalar o surgimento de novas técnicas e mecanismos políticos que visam à multiplicação, intensificação, prolongamento e fortalecimento da vida enquanto processo biológico e do homem enquanto espécie. De fato, ao lado das técnicas e mecanismos disciplinares que objetivam a individualização e normalização do corpo enquanto máquina, vemos surgir uma tecnologia que visa à gestão da multiplicidade de homens a partir do acompanhamento, controle e intervenção sobre fenômenos inerentes à população, tais como a natalidade, a mortalidade, as endemias, as epidemias, a fecundidade, a longevidade. De modo que não é somente o homem-corpo, mas também o homem-espécie o alvo desta nova tecnologia, denominada por Foucault, de biopolítica.

Em suma, nestes dispositivos biopolíticos ou de regulamentação administra-se a população por meio da regulação - da busca de "uma espécie de homeóstase" (FOUCAULT, 1999, p. 293) - dos fenômenos que afetam a multiplicidade de indivíduos, tanto no nível individual, como no nível coletivo.

Doravante, ao poder cabe fazer viver - intensificar, melhorar, aperfeiçoar, prolongar e proliferar a vida. É como se o poderio político não se baseasse mais na conquista e manutenção de territórios, mas na qualidade, na força, na potência de sua população. Por isso Foucault dirá que

à velha mecânica do poder de soberania escapavam muitas coisas, tanto por baixo quanto por cima, no nível do detalhe e no nível da massa. Foi para recuperar o detalhe que se deu uma primeira acomodação: acomodação dos mecanismos de poder sobre o corpo individual, com vigilância e treinamento - isso foi a disciplina. [...]. E, depois, vocês têm em seguida, no final do século XVIII, uma segunda acomodação, sobre os fenômenos globais, sobre os fenômenos de população, com os processos biológicos ou biosociológicos das massas humanas (idem, p. 298). 
Esta engrenagem biopolítica, no entanto, tem seus limites. Por um lado, o biopoder corre o risco de suprimir-se ao permitir um excesso do poder soberano de matar - como é o caso da utilização da bomba atômica cuja capacidade de destruição é tão grande que pode atingir até mesmo aqueles que recorrem a ela. E, por outro lado, há o risco de um excesso de biopoder, isto é, a possibilidade de multiplicar, intensificar, proliferar a vida até o ponto em que se produza algo monstruoso, incontrolável e também capaz de um efeito devastador. Por isso Foucault afirma que o biopoder necessita de um mecanismo regulador que permita eliminar os perigos internos e externos ao prolongamento, intensificação e fortalecimento da população.

Neste sentido, este mecanismo regulador fundamenta-se na inserção da função de morte num sistema político que visa fazer viver. Por isso, ao discorrer sobre biopolítica - ou estatização da vida - Foucault não deixa de frisar o paradoxo existente na modalidade biopolítica de exercício político cuja finalidade é multiplicar, proteger, prolongar, fortalecer, intensificar a vida, mas, no entanto, contem em si o direito soberano de fazer morrer, o qual não se restringe ao "assassínio direto, mas também [a] tudo o que pode ser assassínio indireto: o fato de expor à morte, de multiplicar para alguns o risco de morte ou, pura e simplesmente, a morte política, a expulsão, a rejeição, etc.” (FOUCAULT, 1999, p. 306).

Deste modo, o direito de espada do soberano funciona como elemento regulador do poder que visa multiplicar, intensificar e proteger a vida. Em outras palavras, o direito de fazer morrer propicia, corrige e aperfeiçoa a engrenagem biopolítica, mantendo, assim, um delicado equilíbrio entre o excesso de soberania e o excesso de regulamentação. Nesse sentido, Foucault dirá:

A morte do outro não é simplesmente a minha vida, na medida em que seria a minha segurança pessoal; a morte do outro, a morte da raça ruim, da raça inferior (ou do degenerado, ou do anormal), é o que vai deixar a vida em geral mais sadia e mais pura (idem, p. 305).

O filósofo ainda ressalta que o fazer morrer na lógica biopolítica requer a caracterização de certas figuras como monstros, seres desviantes cuja existência constitui um perigo, uma ameaça vital para o restante da sociedade, mas também como uma excrescência que deturpa e corrompe aqueles que o cercam. Cabe indagar se essas figuras tornam-se mais visadas por causa do avanço normalizador sobre a população, ou se elas são especificamente produzidas para que a potência mortífera própria da soberania tenha a ocasião de se manifestar.

Decerto Foucault está ciente de que a vida sempre exerceu alguma influência sobre os processos históricos. Contudo, esta relação se dava sob o signo da morte, da vida que se esvaía pela fome ou pela doença. Porém, o desenvolvimento econômico, o aumento da oferta de alimentos, o avanço nas tecnologias médicas reduziram o número de mortes. A morte tornou-se, pois, um evento mais controlável. Então é com a vida que a política deve lidar, viver adquire um novo sentido, novo estatuto; não se trata mais da ausência de intervenção, do deixar acontecer, mas de preocupar-se com que tipo de vida se leva, quais fatores atuam ou pelo menos influenciam na qualidade de vida, em sua força, em sua potência, em sua saúde. 
Ora, perguntamo-nos se este protagonismo da vida e seus fenômenos no campo da política implicam no nivelamento, no imediatismo entre o mero viver e o habitar o âmbito político, não havendo diferença entre os seres humanos e outros seres vivos, de forma que na estratégia biopolítica ocorreria uma animalização do homem, reduzindo, ou melhor, privilegiando em sua existência política os aspectos vitais mais básicos em detrimento das faculdades mais complexas como a linguagem, a memória, próprias do que consideramos humano, pois como frisa Foucault: "O homem, durante milênios, permaneceu o que era para Aristóteles: um animal vivo e, além disso, capaz de existência política; o homem moderno é um animal, em cuja política, sua vida de ser vivo está em questão" (FOUCAULT, 1988, p. 156).

Temos, pois, a justaposição dos modelos soberano, disciplinar e regulamentador nesta nova tecnologia política vigente no contemporâneo. O qual, mais do que uma construção paradoxal, refere-se antes a um estado de coisas muito mais complexo para o qual as velhas grades de inteligibilidade - fundadas no é isto ou aquilo - já não são adequadas. Deste modo, para Foucault,

as coisas não devem de forma nenhuma ser compreendidas como a substituição de uma sociedade de soberania por uma sociedade de disciplina, e mais tarde de uma sociedade de disciplina por uma sociedade, digamos de governo. Temos, de fato, um triângulo - soberania, disciplina e gestão governamental -, uma gestão governamental cujo alvo principal é a população e cujos mecanismos essenciais são os dispositivos de segurança [ou regulamentadores] (2008, p. 143).

Ainda que o Estado nazista tenha generalizado o funcionamento biopolítico e levado ao paroxismo o direito soberano de matar, para Foucault, não se trata do aparecimento repentino de uma estrutura singular, de uma abominável exceção. O jogo entre o direito de espada e os mecanismos do biopoder está inscrito no funcionamento dos Estados cujo sistema político está centrado na vida, pois a função de morte regula e propicia o funcionamento do biopoder na medida em que "a morte dos outros é o fortalecimento biológico da própria pessoa na medida em que ela é membro de uma raça ou de uma população" (FOUCAULT, 1999, p. 308).

Aparentemente não é possível conciliar a visão de Hannah Arendt e Michel Foucault acerca da presença da ação soberana de fazer morrer e deixar viver nos Estados modernos. Pois, para a primeira a violência estatal está diretamente relacionada ao vácuo legal, isto é, diante da ausência de leis ou mesmo da ineficácia do ordenamento vigente é que o direito de espada do soberano pode se manifestar. Já para o segundo, a estatização da vida, a estrutura biopolítica de exercício do poder requer mecanismos que instaurem a função de morte, cuja finalidade é propiciar e aperfeiçoar o sistema político centrado na vida.

Entretanto, é interessante notar que ao fazer seu diagnóstico da situação dos apátridas Hannah Arendt evidencia o processo paulatino de desqualificação destas pessoas que não possuem a proteção de um Estado. Com efeito, a condição dos apátridas é progressivamente 
dilapidada até que estas pessoas não passem de seres viventes sobre os quais se abate a violência estatal, processo que remete à produção do muçulmano nos campos de concentração nazista. Segundo Giorgio Agamben, o muçulmano é aquele que se encontra numa zona indiscernível entre a vida e a morte; é aquele cujo abatimento, prostração e silenciosa resignação o transformaram num "cadáver ambulante". Assim, "o muçulmano marcava de algum modo o instável umbral em que o homem passava a ser não homem” (AGAMBEN, 2008, p. 55).

Pois é esta figura paradoxal do muçulmano que podemos encontrar no limiar derradeiro do avanço biopolítico sobre uma determinada população. Como vimos com Foucault, o exercício político centrado na vida requer a distinção, numa determinada multiplicidade, de alguns elementos cujas mortes significarão o fortalecimento, a intensificação da vida do conjunto da população. Ou nas palavras de Agamben, estas distinções referem-se às divisões biopolíticas móveis que

isolam, de cada vez, no continuum da vida, uma zona ulterior, que corresponde a um processo de Entwürding [aviltamento] e de degradação cada vez mais acentuado. Dessa forma, o não ariano transmuta-se em judeu, o judeu em deportado (umgesiedelt, ausgesiedelt), o deportado em internado (Häftling) até que, no campo, as cesuras biopolíticas alcancem o seu limite último. O limite é o muçulmano (2008, p. 90).

Ora, se para Hannah Arendt o funcionamento normal dos Estados modernos não permite - ou pelo menos considera uma excrescência - o exercício do direito soberano de fazer morrer e deixar viver, ela aponta, no entanto, que a entrada da vida na política é a condição de possibilidade da manifestação do direito de espada do soberano nos Estados modernos. Ou seja, é sobre a vida nua dos homens, "a abstrata nudez de ser unicamente humano" (ARENDT, 1989, p. 331) que se abate a violência estatal em sua faceta mais monstruosa.

Assim, guardadas as especificidades conceituais de Michel Foucault e Hannah Arendt e ainda que a filósofa alemã não tenha utilizado o termo biopolítica, sua reflexão crítica acerca da condição dos apátridas - meros seres viventes expostos ao aniquilamento - alude ao funcionamento de um poder que visa à vida e cujo alvo é a população, mas que encontra na produção da vida matável - ou fabricação de cadáveres ambulantes - seu instrumento regulador.

\section{Referências Bibliográficas}

AGAMBEN, Giorgio. O muçulmano. In: O que resta de Auschwitz: o arquivo e a testemunha (Homo Sacer III). Tradução de Selvino J. Assmann. São Paulo: Boitempo, 2008, p. 49 - 91. 
ARENDT, Hannah. O declínio do Estado-nação e o fim dos direitos do homem. In Origens do totalitarismo. Tradução Roberto Raposo. São Paulo: Companhia das Letras, 1989, p. $300-336$.

FOUCAULT, Michel. Aula de $1^{\circ}$ de fevereiro de 1978. In: Segurança, Território, População: curso dado no Collège de France (1977-1978). Tradução de Eduardo Brandão. São Paulo: Martins Fontes, 2008, p. 117 - 154.

Aula de 17 de março de 1976. In: Em Defesa da Sociedade: curso dado no Collège de France (1975-1976). Tradução de Maria Ermantina Galvão. São Paulo: Martins Fontes, 1999 , p. $285-326$.

História da sexualidade I: A vontade de saber. Tradução de Maria Thereza da Costa Albuquerque e J. A. Guilhon Albuquerque. Rio de Janeiro: Graal, 1988. 